\title{
CALAGEM E ADUBAÇÃO NO CRESCIMENTO DO CAPIM MOMBAÇA EM RORAINÓPOLIS, RORAIMA
}

\section{LIMING AND FERTILIZATION ON GROWTH OF MOMBAÇA GRASS IN RORAINÓPOLIS, RORAIMA}

Jheniffer Gomes Souza $\mathbf{1}^{\mathbf{1}}$

Francisco Péricles Galúcio Aires ${ }^{2}$

Plínio Henrique Oliveira Gomide ${ }^{3}$

Járisson Cavalcante Nunes 4

RESUMO: Os solos de Roraima, principalmente na região Sul, possuem elevada acidez. Estudos que demonstrem os efeitos da calagem e adubação em áreas de pastagem são incipientes no município de Rorainópolis. Desse modo, objetivou-se com esta pesquisa avaliar o efeito da calagem e adubação no crescimento de plantas de capim mombaça. O experimento foi conduzido no período de agosto de 2018 a fevereiro de 2019. O delineamento experimental foi em blocos casualizados, em esquema de parcela subdividida, com oito repetições. Nas parcelas foram aleatorizados os seguintes tratamentos: T1= calagem mais nitrogênio e potássio; T2= calagem mais nitrogênio, fósforo e potássio e T3= nitrogênio e potássio. Nas subparcelas foram avaliadas três épocas de corte, 69, 99 e 129 dias após a semeadura. Nas plantas de capim mombaça foram avaliados os seguintes indicadores de produção: altura da planta, número de perfilho, massa fresca da parte aérea e massa seca da parte aérea. A prática da calagem associada a adubação nitrogenada, fosfatada e potássica promoveu maior crescimento das plantas de capim mombaça, possibilitando, no primeiro e segundo corte, a obtenção de 20,7 e $11,3 \mathrm{t} \mathrm{ha}^{\mathbf{1}}$ de massa fresca, respectivamente. O manejo adequado do solo com calagem e adubação propicia melhor desenvolvimento de plantas de capim mombaça no município de Rorainópolis, Roraima.

Palavras-chave: Correção do solo, Fertilizantes, Forrageira, Panicum maximum.
ABSTRACT: The soils of Roraima, mainly in the southern region, have high acidity. Studies demonstrating the effects of liming and fertilization on pasture areas are incipient in the municipality of Rorainópolis. Thus, the objective of the research was to evaluate the effect of liming and fertilization on growth of mombaça grass. The experiment was conducted from August 2018 to February 2019. The treatments were arranged in randomized blocks with eight replications. The following treatments were randomized "split plot", in the plots: $\mathrm{T} 1=$ liming plus nitrogen and potassium; T2 = liming plus nitrogen, phosphorus and potassium and T3 = nitrogen and potassium. In the subplots, three cutting seasons were evaluated, 69, 99 and 129 days after sowing. In the mombaça grass plants the following yield indicators were evaluated: plant height, tillering number, fresh shoot mass and dry shoot mass. The practice of liming associated with nitrogen, phosphate and potassium fertilization promoted greater growth of mombaça grass plants, making it possible, in the first and second cut, to obtain 20.7 and 11.3 t ha-1 of fresh mass, respectively. Proper soil management with liming and fertilization provides better development of mombaça grass plants in the municipality of Rorainópolis, Roraima.

Keywords: Soil correction, Fertilizer, Forage, Panicum maximum. 


\section{INTRODUÇÃO}

O Brasil possui aproximadamente 160 milhões de hectares de pastagens, o equivalente a $45 \%$ de todo o território nacional, sendo 99.954.268,22 hectares de pastagens cultivadas em boas condições (63\%), 46.847.429,925 hectares de pastagens naturais (30\%) e 11.821.005,873 hectares de pastagens em áreas com manejo inadequado (7\%). A área de pastagens do estado de Roraima é de 1.110.592,429 de hectares, sendo 376.083,805 hectares de pastagens cultivadas e 663.576,168 hectares de pastagens naturais. Do total da área de pastagens do estado de Roraima, 70.932,456 hectares de pastagens necessitam de maior investimento em relação ao manejo (IBGE, 2017).

No estado de Roraima a pecuária iniciou na metade do século XVII, com uso das pastagens nativas. Nesta época, os donos de terras faziam apenas as derrubadas e queimas de suas áreas de florestas e em seguida semeava a lanço as sementes das forrageiras. A queima excessiva das áreas de pastagens ou seu manejo inadequado podem causar a degradação física, química e biológica do solo, deixando assim, uma pastagem sem vigor, levando a sua degradação. Assim, a recuperação dessas pastagens degradadas, auxiliará na ampliação da produtividade no campo, sem que haja o aumento de novas áreas para pastagens (Carvalho et al., 2017).

Uma forma de recuperação de pastagens degradadas é uso da calagem e adubação. A prática da calagem eleva o $\mathrm{pH}$ do solo, neutraliza o alumínio tóxico, fornece cálcio e magnésio para as plantas, aumenta a capacidade de troca de cátions, podendo contribuir para elevação da atividade microbiana. A adubação aumenta a disponibilidade de nutrientes no solo, favorece o crescimento da gramínea forrageira, melhora a densidade, proporcionando maior cobertura e diminuído a erosão do solo (Carvalho et al., 2017).

Os solos de Roraima, principalmente da região Sul, possuem elevada acidez. De acordo com Malavolta (2006), a baixa fertilidade encontrada nos solos ácidos está associada, em grande parte, à pobreza em bases trocáveis e ao excesso de alumínio e manganês. Como forma corretiva destes problemas no solo, a calagem proporciona elevação do pH, neutralização do alumínio tóxico, fornece cálcio e magnésio, propicia maior desenvolvimento do sistema radicular das plantas, melhora a eficiência de uso dos nutrientes e da água que estão no solo, bem como melhora a atividade biológica do solo (NATALE et al., 2012).

Estudos em diversas regiões do Brasil têm avaliado o efeito da calagem nas alterações químicas do solo (COSTA et al., 2012; SOUZA et al., 2016; BERNARDI et al., 2018). No estado de Roraima, especialmente no município de Rorainópolis, são inexistentes as informações que demonstrem os efeitos da calagem e da adubação em áreas de pastagem. Desse modo, o objetivo da pesquisa foi avaliar o efeito da calagem e adubação no crescimento do capim Mombaça (Panicum maximum cv. Mombaça).

\section{MATERIAL E MÉTODOS}

O experimento foi conduzido entre os meses de agosto de 2018 a fevereiro de 2019, no município de Rorainópolis - RR, na vicinal 14, no sítio Bela Vista, situado nas coordenadas $00^{\circ} 45^{\prime} 07^{\prime \prime}$ latitude e 
60³4'17'’longitude. A região Sul de Roraima tem predominância absoluta de florestas tropicais úmidas em relevo de planície e baixos platôs. O tipo climático predominante é o “Af”, esse clima possui um elevado índice de precipitação anual (> $2.000 \mathrm{~mm}$ ). A temperatura média do município é da ordem de $25{ }^{\circ} \mathrm{C}$ (Alvares et al., 2013).

Durante o período experimental, a precipitação pluvial foi de $672,5 \mathrm{~mm}$, com 205, 138, 92, 98, 70, 43 e 26,5 mm nos meses de agosto, setembro, outubro, novembro e dezembro de 2018 e janeiro e fevereiro de 2019, respectivamente. A temperatura média do ar do foi de $27,58{ }^{\circ} \mathrm{C}$.

A área experimental apresenta relevo plano, levemente ondulado. Em 1986 a vegetação nativa foi derrubada e queimada para realização dos plantios de arroz e feijão, depois da retirada dessas culturas, ficou em pousio. Em 2015 e 2016, a área foi reintegrada ao sistema produtivo, sendo cultivados milho, feijão e macaxeira em sistema convencional. Apenas na cultura do milho foi realizada adubação nitrogenada (ureia) e fosfatada (superfosfato simples), nas demais culturas o único manejo foram às arações.

Em 2017 a área ficou em pousio, sendo em 2018 utilizada para o presente estudo. Antes do manejo da área foi levantada a vegetação espontânea, sendo identificadas as seguintes plantas daninhas: malicia (Mimosa pudica L.), jurubeba (Solanum fastigiatum), malva (Malva sylvestris L.) e relógio (Sida sp), algumas gramíneas como o quícuio (Urochloa humidicola) e Brizantão (Urochloa brizantha).

Para caracterização química do solo foram coletadas amostras com auxílio de um trado holandês na profundidade de 0 0,20 m, sendo coletadas 15 amostras simples, em zig-zag, para formar uma composta. A implantação do experimento se deu em 14 de outubro de 2018. Antes da implantação do experimento, o solo apresentava os seguintes atributos (EMBRA$\mathrm{PA}, 2011): \mathrm{pH}\left(\mathrm{CaCl}_{2}\right)=4,4 ; \mathrm{P}=2,0 \mathrm{mg}$ $\mathrm{dm}^{-3} ; \mathrm{K}=0,10 \mathrm{cmol}_{\mathbf{c}} \mathrm{dm}^{-3} ; \mathrm{Ca}=1,50$ $\mathrm{cmol}_{\mathbf{c}} \mathrm{dm}^{-3} ; \mathrm{Mg}=0,8 \mathrm{cmol}_{\mathbf{c}} \mathrm{dm}^{-3} ; \mathrm{Al}^{3+}=$ $0,25 \mathrm{cmol}_{\mathbf{c}} \mathrm{dm}^{-3} ; \mathrm{H}^{+}+\mathrm{Al}^{3+}=3,6 \mathrm{cmol}_{\mathbf{c}} \mathrm{dm}^{-}$ 3; soma de bases $=2,41 \mathrm{cmol}_{\mathbf{c}} \mathrm{dm}^{-3}$; CTC $\left(\mathrm{pH} \mathrm{7,0)}=6,01 \mathrm{cmol}_{\mathbf{c}} \mathrm{dm}^{-3} ;\right.$ CTCefetiva $=$ $2,66 \mathrm{cmol}_{\mathbf{c}} \mathrm{dm}^{-3}$; saturação por bases = 40,98\%; saturação por alumínio = 9,41\%; matéria orgânica $=11,0 \mathrm{~g} \mathrm{~kg}^{-1}$; areia $=$ $60 \%$; silte $=6,8 \%$ e argila $=33,2 \%$.

Para o preparo da área realizou-se três arações para a incorporação e corte de algumas plantas daninhas, logo após a primeira aração, nos tratamentos com calagem (em 12 de agosto de 2018), aplicou-se 130 kg de calcário calcítico tendo o PRNT 86\% em área total de $690 \mathrm{~m}^{2}$ (1,3 t ha ${ }^{-1}$ de calcário). Foi utilizado o método de saturação por base ( $\mathrm{V}=60 \%)$ para determinação da quantidade de calcário a ser utilizada na área, sendo o mesmo aplicado a lanço e incorporado com uma grade de arado acoplado a um trator.

O delineamento experimental foi em blocos casualizados, em esquema de parcela subdividida, com oito repetições. Nas parcelas foram aleatorizados os seguintes tratamentos: $\mathrm{T} 1=$ calagem mais nitrogênio e potássio $(\mathrm{CNK})$; T2= calagem mais nitrogênio, fósforo e potássio (CNPK) e T3= NK. Nas subparcelas foram avaliadas três épocas de corte, 69, 99 e 129 dias após a semeadura. As parcelas experimentais foram delimitadas nas dimensões de 6,5 $\mathrm{m} \times$ 
3,0 m (largura e comprimento) possuindo $1,0 \mathrm{~m}$ de corredor, totalizando $19,5 \mathrm{~m}^{2}$. A adubação de fundação da pastagem foi realizada com fósforo (nos tratamentos que continha o insumo), utilizando como fonte superfosfato simples, na dose de $90 \mathrm{~kg} \mathrm{ha}^{-}$ ${ }^{1}$ de $\mathrm{P}_{2} \mathrm{O}_{5}$, aplicado a lanço no dia 02 de outubro de 2018, fazendo sua incorporação com auxílio de grade de arado acoplado a um trator. O fertilizante fosfatado possui em sua composição $18 \%$ de $\mathrm{P}_{2} \mathrm{O}_{5}, 16 \%$ de $\mathrm{Ca}, 12 \%$ de $\mathrm{S}$, e $35,9 \%$ de $\mathrm{SO}_{4}$. A semeadura foi realizada no dia 14 de outubro de 2018, manualmente, a lanço, e as sementes foram distribuídas de maneira uniforme em toda parcela experimental.

O controle das plantas invasoras foi realizado com a aplicação do herbicida Tucson ${ }^{\circledR}$, sendo utilizado $180 \mathrm{~mL}$ do produto em 20 L de água, aplicado após 30 dias da semeadura por meio de um pulverizador costal, época em que a forrageira já estava estabelecida no campo.

A adubação de cobertura foi realizada com 40 dias após a semeadura da forrageira com aplicação de ureia ( $45 \%$ de $\mathrm{N})$, e o cloreto de potássio ( $58 \%$ de $\mathrm{K}_{2} \mathrm{O}$ ), tendo sua aplicação feita a lanço após a dessecação das plantas invasoras. Foram aplicados $100 \mathrm{~kg} \mathrm{ha}^{-1}$ de ureia e $40 \mathrm{~kg} \mathrm{ha}^{-1}$ de $\mathrm{K}_{2} \mathrm{O}$. A ureia foi dividida em três aplicações: a primeira de $50 \mathrm{~kg} \mathrm{ha}^{-1}$, a segunda aplicação, feita um mês após a primeira, com $25 \mathrm{~kg} \mathrm{ha}^{-1}$ e a terceira aplicação, feita um mês após a segunda, com $25 \mathrm{~kg} \mathrm{ha}^{-1}$. Para aplicação das doses mencionadas, foram considerados os atributos do solo antes da instalação do experimento, que apresentavam teores muito baixos de fósforo, e baixos de potássio e matéria orgânica (ALVAREZ V. et al., 1999) e a recomendação de adubação proposta por Gomide et al. (2016).

A espécie utilizada de forrageira foi o capim Mombaça (Panicum maximum cv. Mombaça), por ser uma das gramíneas forrageiras mais utilizadas pelos pecuaristas do município, essa gramínea é resistente à seca, oferece alto valor nutricional, médio porte e resistente a cigarrinha da pastagem (FARIA et al., 2015). A quantidade de sementes lançada nas parcelas foi calculada de acordo com o valor cultural (VC), $25 \mathrm{~kg}$ ha-1.

Para avaliar a relevância da correção e das adubações nitrogenada, fosfatada e potássica na produção da forrageira foram avaliados os seguintes indicadores de produção: altura da planta (AP), número de perfilho (NP), massa fresca da parte aérea (MF) e massa seca da parte aérea (MS).

Para avaliação das variáveis supramencionadas, como critério de amostragem, foi utilizada uma estrutura metálica quadrada com dimensões conhecidas de $0,5 \times 0,5 \mathrm{~m}$ a qual foi lançada duas vezes em cada parcela de forma aleatória, sendo avaliado as plantas que estavam no interior da estrutura mencionada. Para determinação da altura das plantas, em cada amostragem (duas por parcela), foram feitos feixes, e a altura das plantas do feixe foi mensurada com uma trena graduada em milímetros, mensurada do solo até a extremidade das folhas. Além da altura da forrageira, o número de perfilho foi obtido através da contagem manual de todas as plantas que estavam dentro da estrutura metálica quadrada. As plantas foram ceifadas a $30 \mathrm{~cm}$ do solo com auxílio de um cutelo, em seguida foram pesadas com o auxílio de uma balança digital para deter- 
minação da massa fresca da parte aérea (MF).

Logo após os cortes foi feito o nivelamento de cada parcela, com uma roçadeira costal mantendo a altura dos $30 \mathrm{~cm}$ do solo, retirou-se o material para ser aplicada a adubação nitrogenada e potássica. Após a colheita as amostras foram identificadas e embaladas em sacos de papel. As amostras foram colocadas em estufa de circulação forçada à temperatura entre $60 \mathrm{e}$ $65^{\circ} \mathrm{C}$ por $72 \mathrm{~h}$ para determinação da massa seca da parte aérea do capim Mombaça.

Os resultados avaliados foram submetidos à análise de variância e as médias comparadas através do teste Tukey a 5\% de probabilidade, com o uso do programa estatístico SISVAR 5.6 (FERREIRA, 2014). Apesar das idades serem variáveis quantitativas, devendo serem estudadas por regressão, foram definidos poucos pontos para um bom ajuste de uma regressão, motivo pelo qual os autores optaram por aplicar o teste de Tukey.

\section{RESULTADOS E DISCUSSÃO}

Houve efeito significativo da interação entre os fatores para todas as variáveis estudadas. A altura das plantas, nos tratamentos que receberam calagem e adubação nitrogenada, fosfatada e potássica (T2) no primeiro corte avaliado apresentou melhor resultado. No segundo corte não houve diferença significativa entre os tratamentos T1 (1,16 m) e T2 (1,25 m), mas os valores superaram aqueles registrados nos tratamentos sem calagem e adubação com $\mathrm{N}$ e K (0,95 m). No terceiro corte não houve diferença estatística entre os manejos adotados na correção do solo e adubação (Tabela 1).

Avaliando os três cortes em cada tipo de manejo, constata-se que a altura das plantas no T1 no primeiro e no segundo corte não diferiram estatisticamente entre si e apresentaram valores superiores ao encontrado no terceiro corte $(0,84 \mathrm{~m})$. Nos tratamentos que receberam calagem e adubação com N, P e K a maior altura do capim foi registrada no primeiro corte, aos 69 dias após a semeadura (1,68 m), seguido pelo segundo e terceiro corte. Para os tratamentos que não receberam calagem, não houve diferença estatística para altura das plantas

\begin{tabular}{|c|c|c|c|c|c|c|}
\hline \multirow{3}{*}{ Correção } & \multicolumn{3}{|c|}{ Corte } & \multicolumn{3}{|c|}{ Corte } \\
\hline & $\begin{array}{c}1 \\
\text { (69 DAS) }\end{array}$ & $\begin{array}{c}2 \\
\text { (99 DAS) }\end{array}$ & $\begin{array}{c}3 \\
\text { (129 DAS) }\end{array}$ & $\begin{array}{c}1 \\
(69 \text { DAS })\end{array}$ & $\begin{array}{c}2 \\
\text { (99 DAS) }\end{array}$ & $\begin{array}{c}3 \\
(129 \text { DAS })\end{array}$ \\
\hline & \multicolumn{3}{|c|}{ Altura de plantas $(\mathrm{m})$} & \multicolumn{3}{|c|}{ Número de perfilhos } \\
\hline T1: Calagem + NK & $1,04 \mathrm{Ba}$ & $1,16 \mathrm{Aa}$ & $0,84 \mathrm{Ab}$ & $72,81 \mathrm{Aa}$ & $42,00 \mathrm{Bb}$ & $57,06 \mathrm{ABb}$ \\
\hline T2: Calagem + NPK & $1,68 \mathrm{Aa}$ & $1,25 \mathrm{Ab}$ & $0,95 \mathrm{Ac}$ & $87,88 \mathrm{Aa}$ & $84,38 \mathrm{Aab}$ & $72,06 \mathrm{Ab}$ \\
\hline $\begin{array}{c}\text { T3: Sem calagem }+ \\
\text { NK }\end{array}$ & $0,86 \mathrm{Ca}$ & $0,95 \mathrm{Ba}$ & $0,82 \mathrm{Aa}$ & $25,69 \mathrm{Bb}$ & $45,13 \mathrm{Ba}$ & $42,00 \mathrm{Ba}$ \\
\hline
\end{tabular}

Tabela 1: Altura de plantas e número de perfilhos de Panicum maximum cv. Mombaça em função de diferentes correções do solo submetidas ao corte aos 69, 99, 129 dias após a semeadura (DAS). Médias seguidas de mesma letra, maiúscula na coluna e minúscula na linha, não diferem entre si pelo teste de Tukey a 5\% de probabilidade. 
entre os três cortes avaliados (Tabela 1).

Os resultados indicam que quando realizada correção e adubação com NPK, a forrageira incrementou sua produção em massa fresca e crescimento, podendo ser realizado até três cortes aos 129 dias após a semeadura com altura de plantas média de $1,29 \mathrm{~m}$.

Conforme mencionado na metodologia, o T2 distinguiu dos demais tratamentos por apresentar fósforo (P) em sua composição. Em solos tropicais, o P é considerado o nutriente com maior importância, apesar de que as plantas absorvam maior quantidade dos outros macronutrientes (COSTA et al., 2008). As funções do P estão relacionadas a fotossíntese, a respiração, ao armazenamento e transferência de energia (NOVAIS et al., 2007), que pode contribuir positivamente no crescimento e desenvolvimento das plantas, inclusive do capim mombaça. Além da calagem e adubação, o bom aporte hídrico do solo, principalmente no primeiro e segundo corte onde foi detectado um índice pluviométrico de 113 $\mathrm{mm}$, os nutrientes possivelmente estavam mais disponíveis em solução do solo propiciando incrementos nas variáveis biométricas da forrageira. Após o segundo corte, a precipitação pluviométrica acumulada foi de apenas $26,5 \mathrm{~mm}$, que pode ter contribuindo para menor umidade do solo e consequentemente, menor desenvolvimento da parte aérea das plantas.

Os macronutrientes como: nitrogênio (N) e potássio (K) são os mais absorvidos pelas plantas onde $\mathrm{N}$ acelera $\mathrm{O}$ desenvolvimento vegetal da parte aérea da planta, agrega maior quantidade de biomassa por unidade de área, portanto, amplia a produção animal (SANTOS et al., 2016). Estudo realizado em São Paulo, em Ilha Solteira, mostrou que quando se utiliza da adubação nitrogenada no capim Mombaça, o mesmo apresenta resultados significativos e um maior desenvolvimento da parte aérea (GALINDO et al., 2018).

O potássio é um elemento fundamental para a nutrição das plantas, responsável por uma série de funções fisiológicas e metabólicas, tais como: ativação de enzimas, fotossínteses, translocação de assimilados, taxa de transpiração das plantas, absorção de nitrogênio e síntese proteica. Com isso, sua baixa disponibilidade torna-se um limitante em sistema de produção com utilização intensiva de solo (ANDRADE et al., 2000).

Grande parte dos solos do Brasil apresentam limitações quanto às características químicas do solo, desse modo, a adubação das pastagens é algo decisivo para a produção da forrageira e, com isso, há um incremento da capacidade de suporte animal bem como do ganho de peso vivo por hectare (REZENDE et al., 2016).

Estudo realizado no estado do Tocantins, avaliando adubação nitrogenada e potássica na produtividade do capim Mombaça sobre adubação fosfatada, a maior altura da forrageira encontrada foi de 100,6 cm na dose 201,06 kg de $\mathrm{P}_{2} \mathrm{O}_{5}$ observada nos tratamentos sob adubação de cobertura (FARIA et al., 2015). Este estudo corrobora com os resultados encontrados no capim Mombaça uma vez que obtivemos valores 
médios de altura de $129 \mathrm{~cm}$ no tratamento com calagem, fósforo, ureia e cloreto de potássio.

Cunha et al. (2010) avaliando a produtividade do mombaça em função de diferentes níveis de nitrogênio, constataram que houve um incremento na altura do perfilho a partir da terceira e quarta avaliação, com aumento de $10 \%$, diferentemente do que foi encontrado em nosso estudo, onde observou-se redução para esta variável do segundo para o terceiro corte, com decréscimo de $33 \%$ em função do período de estiagem.

Para a variável número de perfilhos no primeiro corte os tratamentos T1 $(72,81)$ e T2 $(87,88)$ não apresentaram diferença estatística entre si sendo superiores ao T3 $(25,69)$. No segundo corte o T2 foi superior aos demais tratamentos. No terceiro corte os tratamentos 1 e 2 foram semelhantes estatisticamente, mas o $\mathrm{T} 2$ $(72,06)$ foi superior ao T3 $(42,00)$ (Tabela 1). No tratamento T1, o maior número de perfilhos foi registrado no primeiro corte, com média de 72,8 perfilhos. No T2, não houve diferença estatística entre o número de perfilhos registrados no primeiro e segundo corte, porém os valores do primeiro corte superaram os valores registrados no terceiro corte. Nos tratamentos sem calagem e adubação com $\mathrm{N}$ e K, as maiores quantidades de perfilhos foram registradas aos $99(45,13)$ e 129 $(42,00)$ dias após a semeadura, no segundo e terceiro corte, respectivamente (Tabela $1)$.

Os dados demostram quando realizada prática da calagem e adubação com NPK o número de perfilhos é superior, quando não realizada as mesmas práticas a forrageira não consegue se estabelecer. O T2 obteve melhor resultado com número de perfilhos médio dos três cortes de 81,44.

O fósforo possui relevante papel nas plantas, auxiliando no desenvolvimento do sistema radicular e no perfilhamento das gramíneas, sendo que esse elemento desempenha grande importância sobre o número e o peso de perfilhos, por ser essencial à maior produtividade e persistência das forrageiras e à grande produção de massa seca; portanto, sua deficiência reduz a capacidade de produção das pastagens (DIAS et al., 2015).

Quando há omissão de nutriente a gramínea demostra alguns indicativos visuais como o amarelecimento das folhas jovens, perda de vigor, estreitamento da folha entre outros indicativos. A deficiência de P é a limitação nutricional mais generalizada ao desenvolvimento de forrageiras em solos das regiões tropicais (GARCIA et al., 2011).

Estudos realizados por Prado et al. (2011), avaliando o desempenho do capimtanzânia cultivado em solução nutritiva com omissão de macronutrientes demonstram que a omissão de fósforo promove prejuízos no crescimento da planta e na absorção de nutrientes. Este efeito refletiu em sintomas característicos de deficiência de fósforo, com aparecimento de folhas mais estreitas e uma diminuição no número de perfilhos.

De acordo com Costa et al. (2016), diferentes níveis de adubação fosfatada sobre a produção de forragem e características morfológicas e estruturais Trachypogon plumosus, promove incremento no número de perfilhos na dose 
de $90 \mathrm{~kg} \mathrm{ha}^{-1}$, com média em oito períodos avaliados de 1.053, valores superiores aos registrados nesta pesquisa.

Os resultados encontrados por Cabral et al. (2016), avaliando a resposta da Urochloa brizantha cv. Marandú a fertilizantes nitrogenados associados ao fosfato natural reativo verificaram que a quantidade de perfilhos aumentou linearmente quando substituído a ureia por sulfato de amônio.

Para a variável matéria fresca da parte aérea (MF) observou-se efeito significativo entre os tratamentos avaliados. As plantas do T2, no primeiro e segundo corte apresentaram massa fresca da parte aérea superior aos demais tratamentos. No terceiro corte, as diferentes formas de manejo da adubação e calagem não resultou em aumento expressivo da massa fresca da parte das plantas de capim mombaça (Tabela 2).

Ao comparar os valores médios de massa fresca do capim mombaça entre os diferentes cortes, observa-se que nos tratamentos que receberam calagem e adubação com N, P e K os maiores valores foram registrados no primeiro corte, aos 69 dias após a semeadura (20735,00 $\mathrm{kg} \mathrm{ha}^{-\mathbf{1}}$ ). Ao relacionar o valor médio obtido no T2 (12.435,00 kg ha-1) com o valor registrado no T1, constata-se um incremento de massa fresca de $185 \%$ em relação ao tratamento que não recebeu adubação fosfatada. Esse incremento é muito significativo, viabilizando aumento da capacidade forrageira para consumo animal, o que poderá trazer satisfatório aumento do peso animal.

Quando realizado o preparo do solo de forma correta, com calagem e adubação de cobertura e aplicação do fósforo na im- plantação da forrageira, a pastagem terá um desenvolvimento do sistema radicular mais efetivo, podendo buscar água nas camadas mais profunda do solo, terá mais número de perfilhos aumentando a sua biomassa, protegendo o solo dos raios ultravioleta (UVA), aumentando o teor da umidade e da matéria orgânica do solo, melhorando a infiltração de água, porosidade bem como agregação das partículas do solo.

Lopes et al. (2018), avaliaram diferentes doses de potássio na produção de Urochloa brizantha cv. Marandú em adubação de estabelecimento e obtiveram melhor resultado na dose de $250 \mathrm{~kg} \mathrm{ha}^{-1} \mathrm{com}$ média de massa fresca total de $29.762 \mathrm{~kg}$ $\mathrm{ha}^{-1}$, no presente trabalho a média de $12.435 \mathrm{~kg} \mathrm{ha}^{-1}$ foi obtida utilizando dose de $40 \mathrm{~kg} \mathrm{ha}^{-1}$.

Para a variável matéria seca da parte aérea (MS) nota-se diferença significativa entre os tratamentos avaliados. No primeiro e segundo corte o T2 foi o que teve melhor desempenho que aos demais tratamentos (Tabela 2). No segundo corte o tratamento T3 foi bem inferior aos outros tratamentos avaliados. Já no terceiro corte os tratamentos T1, T2 e T3 não apresentaram diferença estatística.

Em todos os tratamentos, a maior massa seca foi registrada no segundo corte. A massa seca das plantas de capim Mombaça aos 66 e 129 dias após o plantio não apresentaram diferenças nas correções 1 e 2. O T2 obteve uma expressiva diferença estatística nos cortes um e três. Já no T3, não houve diferença estatística no primeiro e terceiro corte (Tabela 2).

A calagem e adubação nitrogenada, fosfatada (90 $\mathrm{kg} \mathrm{ha}^{-1}$ de superfosfato simples) 


\begin{tabular}{|c|c|c|c|c|c|c|}
\hline \multirow{3}{*}{ Correção } & \multicolumn{3}{|c|}{ Corte } & \multicolumn{3}{|c|}{ Corte } \\
\hline & $\begin{array}{c}1 \\
\text { (69 DAS) }\end{array}$ & $\begin{array}{c}2 \\
\text { (99 DAS) }\end{array}$ & $\begin{array}{c}3 \\
(129 \mathrm{DAS})\end{array}$ & $\begin{array}{c}1 \\
\text { (69 DAS) }\end{array}$ & $\begin{array}{c}2 \\
\text { (99 DAS) }\end{array}$ & $\begin{array}{c}3 \\
(129 \mathrm{DAS})\end{array}$ \\
\hline & \multicolumn{3}{|c|}{ Massa fresca $\left(\mathrm{kg} \mathrm{ha}^{-1}\right)$} & \multicolumn{3}{|c|}{ Massa seca $\left(\mathrm{kg} \mathrm{ha}^{-1}\right)$} \\
\hline $\mathrm{T} 1:$ Calagem $+\mathrm{NK}$ & $3125 \mathrm{Bab}$ & $7150 \mathrm{Ba}$ & $2770 \mathrm{Ab}$ & $1225 \mathrm{Bb}$ & $4000 \mathrm{Ba}$ & $1180 \mathrm{Ab}$ \\
\hline T2: Calagem + NPK & $20735 \mathrm{Aa}$ & $11275 \mathrm{Ab}$ & $5295 \mathrm{Ac}$ & $4200 \mathrm{Ab}$ & $6400 \mathrm{Aa}$ & $2105 \mathrm{Ac}$ \\
\hline $\begin{array}{c}\text { T3: Sem calagem }+ \\
\text { NK }\end{array}$ & $1340 \mathrm{Ba}$ & $4562,5 \mathrm{Ba}$ & $2380 \mathrm{Aa}$ & $400 \mathrm{Bb}$ & $2550 \mathrm{Ca}$ & $890 \mathrm{Ab}$ \\
\hline
\end{tabular}

Tabela 2: Massa fresca (MF) e seca (MS) da parte aérea de Panicum maximum cv. Mombaça em função de diferentes correções do solo submetidas ao corte aos 69, 99, 129 dias após a semeadura (DAS). Médias seguidas de mesma letra maiúscula na coluna e minúscula na linha não diferem entre si pelo teste de Tukey a 5\% de probabilidade.

e potássica elevou a massa seca da parte aérea da forrageira Mombaça com valor médio dos três cortes de $4.235,00 \mathrm{~kg} \mathrm{ha}^{-1}$. O elemento químico $\mathrm{N}$ possui uma acentuada influência no comportamento estrutural das forrageiras, no comprimento final das folhas e o número de folhas por perfilho, que, em última análise, determinam o índice de área foliar do pasto e sua produção (ROSADO et al., 2014).

Em estudo realizado por Dias et al. (2015), na região norte de Minas Gerais, avaliando a produção do capim Piatã (Brachiaria brizantha) submetidos em diferentes combinações de fosfato obtiveram incremento na produção da matéria seca das folhas, pseudocolmo e da parte aérea do capim Piatã nos segundo e terceiro cortes avaliativos e na média dos cortes, indicando aumento da produção de forragem.

Em um estudo realizado em Roraima por Costa et al. (2018), avaliando produtividade de forrageira e composição química de Stylosanthe capitata cv. Lavradeiro sob diferentes níveis de fósforo, observaram incremento da variável matéria seca verde até a dose de $89 \mathrm{~kg} \mathrm{ha}^{-1} \mathrm{com}$ produção de $3018 \mathrm{~kg} \mathrm{ha}^{-1}$. O presente estudo corrobora com dose de $90 \mathrm{~kg} \mathrm{ha}^{-1}$ de $\mathrm{P}_{2} \mathrm{O}_{5}$, obtendo 4.235,00 kg ha-1 de MS.

\section{CONCLUSÕES}

A prática da calagem associada a adubação nitrogenada, fosfatada e potássica promove maior crescimento das plantas de capim mombaça.

A adubação fosfatada proporcionou maior desenvolvimento das plantas de $\mathrm{Pa}$ nicum maximum cv. Mombaça, resultando em maior altura, maior quantidade de perfilhos e maior massa fresca e seca do capim cultivado no município de Rorainópolis, Roraima.

\section{REFERÊNCIAS BIBLIOGRÁFICAS}

ALVARES, C. A.; STAPE, J. L.; SENTELHAS, P. C.; GONÇALVES, J. L. M.;

SPAROVEK, G. Köppen's climate classification map for Brazil. Meteorologische Zeitschrift, Berlin, v. 22, n. 6, p. 711-728, 2013.

ALVAREZ V., V. H.; NOVAIS, R. F.; 
BARROS, N. F.; CANTARUTTI, R. B.; LOPES, A. S. Interpretação dos resultados das análises de solos. In: RIBEIRO, A.C.; GUIMARÃES, P.T.G.; ALVAREZ V., V.H. (Ed.). Recomendações para o uso de corretivos e fertilizantes em Minas Gerais. 5a aproximação. Viçosa: Comissão de Fertilidade do Solo do Estado de Minas Gerais, 1999. p.25-32.

ANDRADE, A. C.; FONSECA, D. M.; GOMIDE, J. A.; ALVAREZ, V. H. V.; MARTINS, C. E.; SOUZA, D. P. H. Produtividade e Valor Nutritivo do CapimElefante cv. Napier sob Doses Crescentes de Nitrogênio e Potássio. Revista Brasileira de Zootecnia, Viçosa, v. 29, n. 6, p. 1589-1595, 2000.

BERNARDI, A. C. C.; BUENO, J. O. A.; LAURENTI, N.; SANTOS, K. E. L.; ALVES T. C. Efeito da calagem e fertilizantes aplicados à taxa variável nos atributos químicos do solo e custos de produção de pastagem de capim tanzânia manejadas intensivamente. Brazilian Journal of Biosystems Engineering, São Paulo, v. 12, n. 4, p. 368-382, 2018.

CABRAL, C. E. A.; CABRAL, L. S.; SILVA, E. A. B.; CARVALHO, K. S,;

KROTH, B. E. e CABRAL, C. H. A. Resposta da Brachiaria brizantha cv. Marandú a fertilizantes nitrogenados associados a fosfato reativo. Comunicata Scientiae, Bom Jesus, v. 7, n. 1, p. 66-72, 2016.

CARVALHO, W. T. V.; MINIGHIN, D. C.; GONÇALVES, L. C.; VILLANOVA, D. F. Q.; MAURICIO, R. M.; PEREIRA, R. V. G. Pastagens degradadas e técnicas de recuperação: Revisão. Revista PUBVET, Maringá, v. 11, n. 10, p.1036-1045, 2017. COSTA, N. L.; MORAES, A.; CARVA-
LHO, P. C. F.; MAGALHÃES, J. A. Acúmulo de forragem e morfogênes de Trachypogon plumosus sob níveis de fósforo. Revista PUBVET, Maringá, v. 10, n. 5, p. 388-393, 2016.

COSTA, N. L.; PAULINO, V. T.; GIANLUPPI, V.; BENDAHAN, A.B.; MAGALHAES, J. A. Produtividade de foragem e composição química de Stylosanthes capitata cv. Lavradeiro sob níveis de fósforo. Revista PUBVET, Maringá, v. 12, n. 5, p. 1-6, 2018.

COSTA, N. L.; PAULINO, V. T.; MAGALHÃES, J. A.; RODRIGUES, A. N. A.; BENDAHAN, A. B.; NASCIMENTO, L. E. S.; FERNANDES, R. C. P. Resposta de Brachiaria brizantha cv. Xaraés a níveis de calagem. Revista PUBVET, Maringá, v. 6, n. 13, p. 1-10, 2012.

COSTA, S. E. V. G. A.; FURTINI NETO, A. E.; RESENDE, A. V.; SILVA, T. O.; SILVA, T. R. Crescimento e nutrição da brachiária em função de fontes de fósforo. Revista Ciência Agrotecnologia, Lavras, v. 32, n. 5, p. 1419-1427, 2008.

CUNHA, O. F. R.; SANTOS, A. C.; ARAÚJO. L. C.; FERREIRA, E. M. Produtividade do Panicum Maximum (mombaça) em função de diferentes níveis de nitrogênio. Revista da Faculdade de Zootecnia, Veterinária e Agronomia, Porto Alegre, v. 17, n. 1, p. 136-145, 2010.

DIAS, D. G.; PEGORARO, R. F.; ALVES, D. D.; PORTO, E. M. V.; NETO, J. A. S.; ASPIAZÚ, I. Produção do capim Piatã submetido a diferentes fontes de fósforo. Revista Brasileira de Engenharia Agrícola e Ambiental, Campina Grande, v. 19, n. 4, p. 330-335, 2015.

EMBRAPA - EMPRESA BRASILEIRA 
DE PESQUISA AGROPECUÁRIA. Manual de Métodos de Análise do Solo. 3. ed. Rio de Janeiro: Embrapa solos, 2011, 230 p.

FARIA, A. J. G.; FREITAS, G. A.; GEORGETTI, A. C. P.; FERREIRA JÚNIOR J. M.; SILVA, M. C. A.; SILVA, R. R., Adubação nitrogenada e potássica na produtividade do capim Mombaça sobre adubação fosfatada. Journal of Bioenergy and Food Science, Macapá, v. 2, n. 3, p. 98-106, 2015.

FERREIRA, D. F. Sisvar: a Guide for its Bootstrap procedures in multiple comparisons. Revista Ciência Agrotecnologia, Lavras, v. 38, n.2, p. 109-112, 2014.

GALINDO, F. S.; BUZETTI, S.; TEIXEIRA FILHO, M. C. M.; DUPAS, E.; LUDKIEWICZ, M. G. Z. Acúmulo de matéria seca e nutrientes no capim-mombaça em função do manejo da adubação nitrogenada. Revista de Agricultura Neotropical, Cassilândia, v. 5, n. 3, p. 1-9, 2018.

GARCIA, R. A.; MERLIN, A.; TOLEDO, M. Z.; FERNANDES, D. M.; CRUSCIOL, C. A. C.; BÜLL, L. T. Desenvolvimento da aveia branca e disponibilidade de fósforo em razão da aplicação de silicato de potássio. Revista Ceres, Viçosa, v. 58, n. 6, p. 831-837, 2011.

GOMIDE, C. A. M.; PACIULLO, D. S. C.; LEITE, J. L. B.; RESENDE, H. Panicum maximum cvs. Tanzânia e Mombaça para uso em pastejo: produção e custo. EMBRAPA Gado de Leite, Juiz de Fora, 2016. 7 p. (Circular Técnica 113). Disponível em: < https://www.embrapa.br/gadode-leite/busca-de-publicacoes/-/publicacao/ 1063665/panicum-maximum-cvs-tanzania-e-mombaca-para-uso-em-pastejo-pro- ducao-e-custo $>$. Acesso em: 11 de maio de 2020.

IBGE. INSTITUTO BRASILEIRO DE GEIGRÁFIA E ESTATÍSTICA. Censo agropecuário 2017. Disponível em:< https://censoagro2017.ibge.gov.br/templates/censo_agro/resultadosagro/estabelecimentos.html? localidade $=0>$. Acesso em: 11 de maio de 2020.

LOPES, G. H. L.; VILAR, C. C.; USHIWATA, S. Y.; REIS, R. G. E.; SILVEIRA, D. S.; TAFAREL, A. H. Produção de Urochloa brizantha cv. Marandu submetida à adubação potássica de estabelecimento. Campo Digit@l: Revista Ciências Exatas e da Terra e Ciências Agrárias, Campo Mourão, v. 13, n. 1, p. 01-08, 2018. MALAVOLTA, E. Manual de nutrição mineral de plantas. Piracicaba: Ceres, 2006. 638p.

NATALE, W.; ROZANE, D. E.; PARENT, L. E.; PARENT, S. E. Revisão acidez do solo e calagem em pomares de frutíferas tropicais. Revista Brasileira de Fruticultura, Jaboticabal, v. 34, n. 4, p. 1294-1306, 2012.

NOVAIS, R. F.; ALVAREZ V., V. H.;

BARROS, N. F.; FONTES, R. L. F.; CANTARUTTI, R. B.; NEVES, J.C.L. Fertilidade do Solo. Viçosa: SBCS, 2007. 1017 p.

PRADO, R. M.; HOJO, R. H.; AVALHÃES, C. C.; VALE, D.W.; PIMENTEL, U. V. Desempenho do capim-tanzânia cultivado em solução nutritiva com à omissão de macronutrientes. Scientia Agraria Paranaenis, Marechal Cândido Rondon, v. 10, n. 1, p 58-68, 2011.

REZENDE, C. G. B.; SILVA, E. M. B.; SILVA, T. J. A.; CABRAL C. E. A.; SCH- 
LICHTING, A. F. Fosfato natural reativo na adubação do capim piatã em Latossolo Vermelho do Cerrado. Revista Brasileira de Ciências Agrárias, Recife, v. 9, n. 31, p. 55 - 62, 2016.

ROSADO, T. L.; GONTIJO, I.; ALMEIDA, M. S.; ANDRADE, F. V. Fontes e doses de nitrogênio e alterações nos atributos químicos de um Latossolo cultivado com capim-mombaça. Revista Brasileira Ciência do Solo, Viçosa, v. 38, n. 3, p. 840849, 2014.

SANTOS, M. P.; CASTRO, Y. O.; MARQUES, R. C.; MARQUES, D. R. P.; GODOY, M. M.; REGES N. P. R. Importância da calagem, adubações tradicionais e alternativas na produção de plantas forrageiras: Revisão. Revista PUBVET, v. 10, n. 1, p. 1-12, 2016.

SOUZA, F. M.; LEMOS, B. J. M.; OLIVEIRA, J. R. C.; MAGNABOSCO, C. U.; CASTRO, L. M.; LOPES, F. B.; BRUNES, L. C. Introdução de leguminosas forrageiras, calagem e fosfatagem em pastagem degradada de Brachiaria brizanta. Revista Brasileira de Saúde Produção Animal, Maringá, v. 17, n. 3, p. 355-364, 2016. 